Avrupa Bilim ve Teknoloji Dergisi

Özel Sayı, S. 300-306, A ğustos 2019

(C) Telif hakkı EJOSAT'a aittir

Derleme Makale
European Journal of Science and Technology

Special Issue, pp. 300-306, August 2020

Copyright (C) 2020 EJOSAT

Review Article

\title{
Meme Kanseri Teşhis ve Prognozunda Radiomics ile Yapay Zeka Yöntemleri Kullanımı Hakkında Bir İnceleme
}

\author{
Tuba Parlar ${ }^{*}$ \\ ${ }^{1}$ Mustafa Kemal Üniversitesi, Bilgisayar Teknolojileri Bölümü, Antakya, Hatay, Türkiye (ORCID: 0000-0002-8004-6150)
}

(Bu yayın 26-27 Haziran 2020 tarihinde HORA-2020 kongresinde sözlü olarak sunulmuştur.)

(DOI: 10.31590/ejosat.780052)

ATIF/REFERENCE: Parlar, T. (2020). Meme Kanseri Teşhis ve Prognozunda Radiomics ile Yapay Zeka Yöntemleri Kullanımı Hakkında Bir İnceleme. Avrupa Bilim ve Teknoloji Dergisi, (Special Issue), 300-306.

$\ddot{O} \mathbf{z}$

Dünya Sağlık Örgütünün 2020 kanser hastalığı raporuna göre meme kanseri en sık görülen kanser türlerinden biridir. Erken teşhis ve tedavi daha yüksek yaşam şansı ve daha iyi bir yaşam kalitesi için önemlidir. Radiomics, meme kanseri tanısında ve prognozunda yeni ve popüler bir araştırma alanıdır. Manyetik rezonans görüntüleme (MR), mamografi, ultrason (US) ve pozitron emüsyon tomografi / bilgisayarlı tomografi (PET / CT) gibi radyografik görüntüleme yöntemleri ile elde edilen görüntülerin sayısal özellikleri üzerinde çalışır. Radiogenomics ise radiomics veriyi kanserin teşhisi, prognozu ve tahmini destekleyecek çok sayıda genomics veri ile ilişkilendirmeye çalışır. Elde edilen radyografik görüntülerden büyük miktarda kandidatif veri çıkarılarak çok boyutlu büyük veri setleri elde edilir. Nitelik seçimi sınıflandırma doğruluğunu artırmak için değersiz nitelikleri veri setinden çıkaran önemli bir işlevdir. Nitelik seçim yöntemleri ile ayrılan değerli nitelikler makine öğrenme ya da derin öğrenme yöntemleri ile kanserin yakalanması, teşhisi, prognozun değerlendirilmesi amacıyla sınıflandırılır. Son yıllarda birçok araştırmacı yapay zeka yöntemlerinin tıp alanında kullanımının hızla gelişmesiyle bu kantitatif -omics verileri ile radiomics modeller geliştirmek amacıyla çok sayıda çalışma yapmışlardır. Bu inceleme, meme kanseri tanı ve prognozunda makine öğrenme ve derin öğrenme yöntemleri ile kullanılan radiomics ve radiogenomics modelleri hakkında literatür taraması yapmayı amaçlamaktadır. 2012 ile 2020 arasındaki araştırma makaleleri incelenmiş ve radyografik görüntüleme yöntemleri, radiomic nitelik çıkarma yöntemleri, nitelik seçme yöntemleri ve makine öğrenme ve derin öğrenme algoritmalarını kullanarak sınıflandırma yöntemleri sunulmuştur. Son olarak, meme kanseri radiomics modellerinin zorluklarını tartışıyor ve geleceteki bazı araştırma konularını öneriyoruz.

Anahtar Kelimeler: Derin Öğrenme, Makine Öğrenme, Meme kanseri, Radiogenomics, Radiomics.

\section{A Review About Radiomics with Artificial Intelligence Methods in Breast Cancer Diagnosis and Prognosis}

\begin{abstract}
According to the 2020 World Health Organization report on cancer disease, breast cancer is one of the most frequent cancer types. Early diagnosis and treatment are important for higher survival rates and better quality of life. In the diagnosis of breast cancer, radiomics is a new and popular research topic. Radiomics works on the numerical features of images obtained by radiographic imaging modalities such as magnetic resonance imaging (MRI), mammography, ultrasound (US) or positron emission tomography / computed tomography (PET / CT). Radiogenomics tries to associate the radiomics data with genomics data which may improve diagnosis, prognosis and prediction of cancer. Multidimensional large datasets are obtained by extracting large amount of candidative features from the radiographic images. Feature selection is an important task to remove non-valuable features to improve classification accuracy. Using feature selection methods, most valuable features are obtained and classified by using machine learning or deep learning methods to diagnose and prognose cancer. Recently many researchers have studied to develop radiomics models using quantitative "-omics" data with the rapid development of the use of artificial intelligence methods in the field of medicine. This review aims to provide a literature survey of radiomics and radiogenomics models with machine learning and deep learning methods in breast cancer diagnosis and
\end{abstract}

\footnotetext{
* Sorumlu Yazar: Mustafa Kemal Üniversitesi, Bilgisayar Teknolojileri Bölümü, Antakya, Hatay, Türkiye, ORCID: 0000-0002-8004-6150, tparlar@,mku.edu.tr
} 
prognosis. We review research papers published between 2012 and 2020 and represent the radiographic imaging modalities, radiomic feature extraction methods, radiomic feature selection methods and classification methods using machine learning and deep learning algortihms. Finally, we discuss the challenges and propose some future research directions of breast cancer radiomics models.

Keywords: Breast Cancer, Deep Learning, Machine Learning, Radiogenomics, Radiomics.

\section{Giriş}

Dünya Sağlık Örgütü 2018 verilerine göre yaklaşık 18.1 milyon yeni kanser vakası tespit edilmiş ve bunların 9.6 milyonu ölümle sonuçlanmıştır. Dünyadaki her altı ölümden biri kanser nedeniyle gerçekleşmektedir (Ferlay vd., 2019). Meme kanseri en çok görülen kanser türüdür. Meme kanserinde erken tanı ve doğru tedaviye başlamak klinik uygulamalar açısından temel hedeftir. Dünya Sağlık Örgütü 2020 kanser raporuna göre meme kanseri Dünyada dördüncü sırada, ülkemizde ise ikinci sırada yer almaktadır (2020). Maalesef istatistikler kanser vakalarının hızla artmaya devam edeceğini göstermektedir (Şekil 1). Kanserden ölüm oranının düşürülmesi için en önemli klinik değerlendirme erken teşhis ile olmaktadır.

Şekil 1. Birleşmiş Milletler nüfus projeksiyonlarına küresel kanser vaka sayısı 2040 tahmini rakamları (Ferlay vd., 2019).

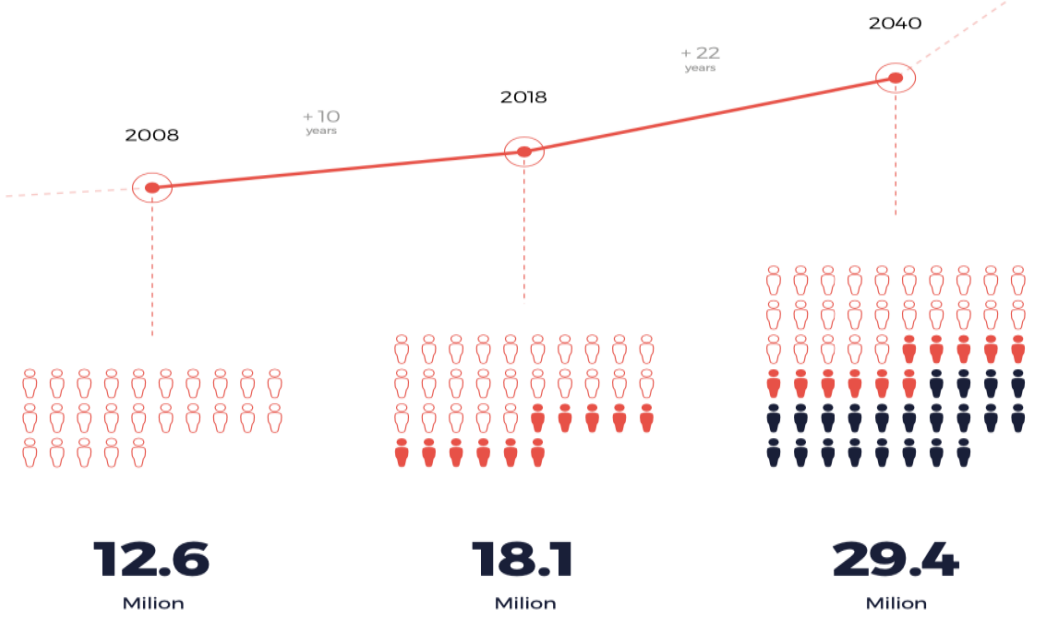

Radyografik görüntüleme teknikleri, hastalarda farklı doku özelliklerinin tespiti ve teşhisi için kullanılan girişimsel olmayan (noninvaziv) güçlü araçlardır. Bu görüntüleme yöntemleri arasında Manyetik Rezonans Görüntüleme (Magnetic Resonance Imaging MR), Mamografi (Mammography), Pozitron Emisyon Tomografisi / Bilgisayarlı Tomografi (Positron Emission Tomography / (Computed Tomography-PET / BT) ve Ultrasonografi (Ultrasound-US) yer alır. Bu görüntüleme tekniklerinin her birinde dokunun normal veya anormal olmasına bağlı olarak farklı kontrast tutulumları olmaktadır. Bir radyolog tanıya farklı kontrast tutulumlarını değerlendirerek varmaya çalışır. Ancak her radyolojik görüntü çok fazla bilgi içermekte ve karmaşık durumlarda sadece geleneksel yöntemlerle karar vermek her zaman mümkün olmamaktadır.

“-omics” eki moleküler biyoloji alanında biyolojik moleküllerin karakterizasyonunu tanımlamak için kullanılır. Örneğin DNA için genomics, RNA için transcriptomics, proteinler için proteomics ve metabolizma için metabolomics terimleri kullanılır. "-omics" verilerinin önemli bir karakteristiği veri madenciliği yapılabilir nitelikte veri içermesidir. “-omics” verileri, üzerinde araştırma yapılabilecek ve hipotez geliştirilebilecek değerde veri içermektedir (Gillies, Kinahan, \& Hricak, 2016). Son yıllarda bu terim tıp alanında oldukça ilginç bir araştırma alanını ifade etmek için kullanılmaya başlandı: Radiomics.

Radiomics, radyografik görüntüleme yöntemleri ile elde edilen görüntülerin numerik özellikleri üzerinde çalışan bir bilim alanı olarak ortaya çıktı. Örneğin bir hastadan alınan çok kesitli ya da üç boyutlu bir görüntü milyonlarca voksel içerebilir. Bir voksel bir Bilgisayarlı Tomografi (BT) görüntüsünün bir resim öğesi olarak tanımlanabilir. Ayrıca bulunan bir tümor, tümorun yapısını, boyutunu, şeklini, dokusunu tanımlayan yüzlerce nitelik (feature) ile ifade edilir. Bütün bu veriler bir klinik sonuçla ilişkilendirilmeye çalışılmaktadır. Radiogenomics ise radiomics veriyi aynı zamanda genetik verilerle ilişkilendirmeye çalışan ve amacı kanserin genotipi ile görüntüleme fenotipi arasındaki ilişkiyi belirlemek olan bir bilim alanıdır.

Son yıllarda bilgisayarlarda daha hızlı işlemcilerin (CPU) kullanımı ve grafik işlemci birimlerinin (GPU) de hesaplamalarda kullanılmasıyla yapay sinir ağları (artificial neural network) algoritmaları geliştirilmesi ile birlikte makine öğrenme modelleri derin öğrenme modellerine doğru evrilmeye başlanmıştır. 2000 yillardan itibaren yaşanan bu gelişmeler son yıllarda özellikle yüksek boyuttaki verilerin sınıflandırılmasında derin öğrenme modellerinin kullanılmasını hızla arttırmıştır. Derin öğrenme yöntemleri kullanılarak klinik ve radyoloji alanında karar destek sistemleri oluşturmak adına çok sayıda araştırma yapılmaktadır (Gillies vd., 2016; V. S. Parekh \& Jacobs, 2019). 
Araştırmacılar için iki populer çalışma alanı bir araya gelmiş ve büyük miktardaki radiomics verisinin analizini makine ve derin öğrenme yöntemleri ile modelleyen çalışmaların sayısı hızla arttmıştır. Son yıllarda özellikle meme kanseri alanında önemli sayıda radiomics araştırması yapılmıştır. Radyografik görüntüleme yöntemleriyle elde edilen verilere genetik biyobelirteçler de eklenerek araştırmalar genişletilmiştir. Bu çalışma ile radiomics uygulamalarında kullanılan radyografik görüntüleme teknikleri ile elde edilen radiomic verinin yapay zeka yöntemleriyle incelenmesi ve analizinin yapılmasında kullanılan yöntem ve teknikleri ortaya koymak üzere bir literatür araştırması yapılmıştır.

\section{Materyal ve Metot}

\subsection{Radiomics}

Radiomics, radyolojik görüntülerin numerik özellikleri üzerinde yapay zeka yöntemlerini kullanarak çalışan ve hızla büyümekte olan bir araştırma alanıdır. Geleneksel yöntemlerle kanser tedavisinin şekline karar vermek için kanserin çıktığı organ, histolojisi, evresi bilgileri kullanılır. Günümüzde artık çeşitli biyobelirteçlerden önemli bilgiler elde edilmektedir. Örneğin meme kanseri için kanser dokusunda östrojen, progesteron ya da HER2 olması kanser prognozunu belirlemek için önemli bilgiler vermektedir.

Klinik olarak kanserin teşhisi için radyografik görüntüleme yöntemlerinden biriyle elde edilen dijital görüntüler ile ilgili bölge tanımlanmaya çalışlır. Bu bölge için bir Radyolog dokunun normal ya da anormal olduğunu belirlemeye çalışır. Klinisyenlerin kullandığı geleneksel yöntemleri vardır. Radiomics devreye girdiğinde istatiktiksel, filtreleme ve morfolojik analizler yardımıyla çok sayıda radiomic nitelikler elde edilir. Böylece çok sayıda radiomic nitelikten oluşan oldukça büyük boyutlu bir veri elde edilir. Daha sonra nitelik seçimi (feature selection) aşamasında bilgilendirici özellik taşıyan önemli nitelikler seçilir. Son adım ise seçilen niteliklerden oluşan veri setini kullanarak hastadaki şüpheli olgunun makine öğrenme yöntemleri ile iyi huylu ya da kötü huylu tümor olarak sinıflandırılmasidır.

Radiomics aşamalarında öncelikle bir radyografik görüntüleme yöntemi ile görüntü elde edilir (Şekil.2-a). Daha sonra elde edilen görüntü üzerinde ilgili bölgeye göre (Region of Interest- ROI) segmentasyon yapılır (Şekil.2-b). Radiomic nitelik çıkarımı (feature extraction) ROI segmentasyonuna göre görüntülerin numerik özelliklerinden, gri yoğunluk seviyelerine, inter-voksel ilişkisine ve şekli vb. özelliklerine göre gerçekleştirilir (Şekil.2-c). Nitelik seçimi aşaması değerli niteliklerin seçimi için oldukça önemlidir. Sınıflandırma doğruluğunu etkileyebilecek radiomic nitelikler nitelik seçim yaklaşımlarına göre elenir ve bir değerli nitelik grubu seçilerek devam edilir (Şekil.2-d). Son aşama olarak, model, eğitim verisi ile bir sınıflandırma modeline girer (Şekil.2-e).

Şekil 2. Radiomics Aşamaları (V. Parekh \& Jacobs, 2016)

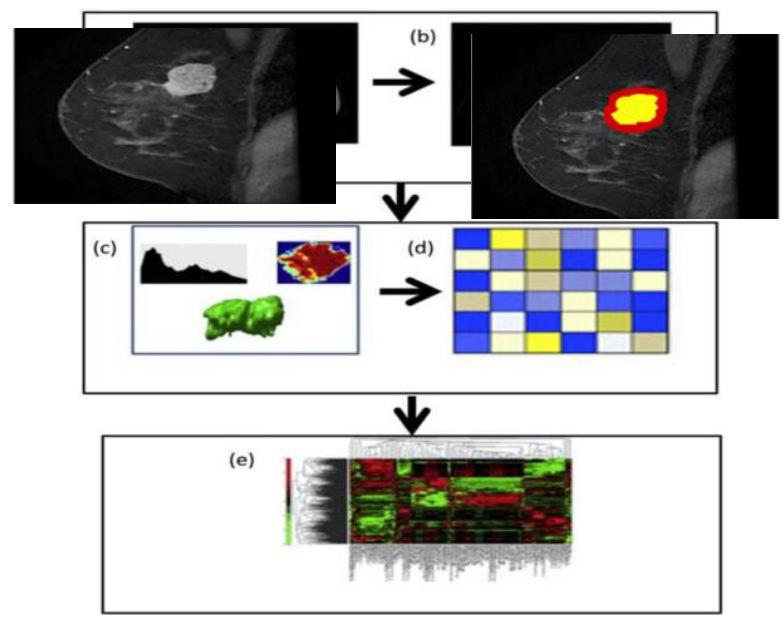

\subsubsection{Radyografik Görüntü Yöntemleri}

Radiomics aşamalarından ilki uygun bir radyografik görüntüleme yöntemi ile görüntü elde edilmesidir. Böylece dijital görüntünün sayısal özellikleri üzerinden çok sayıda kantitatif nitelik elde edilebilir. Bu da tümör fenotipleri hakkında radiomic veri elde edilmesi demektir.

\section{Magnetik Rezonans (MR)}

Meme kanseri tanısında en yaygın olarak kullanılan radyografik görüntüleme yöntemleri mamografi ve ultrasonografidir. Ancak meme MR mamografi ve ultrasonografiden farklı olarak tümor şekli, boyutu, kontürü gibi morfolojik özelliklerin dışında doku karakteristiklerini de parametrik olarak gösterebilmektedir. Meme kanserinde en hassas ve temel görüntüleme yöntemlerinden biri MR olarak görülmektedir. MR görüntüleri kontrast yoğunluğuna göre bir tümörü kategorize etmek için çok sayıda parametrik bilgi sağlar. Meme kanserinde MR görüntülerinin radiomics alanında kullanımında öncü yayınlardan biri Yamamoto ve arkadaşları (Yamamoto, Maki, Korn, \& Kuo, 2012) tarafından yapılmıştır. Günümüzde meme MR görüntüleri difüzyon ağırlıklı görüntüleme (diffusionweighted imaging-DWI) ve dinamik kontrastlı görüntüleme (dynamic contrast-enhanced-DCE) olarak yapılmaktadır. DCE-MRI 
görüntüleri kontrast yoğunluğu parametrelerinden dolayı radiogenomics niteliklerle ilişkilendirilmesi sebebiyle yaygın olarak kullanılmaktadır (Mazurowski, Zhang, Grimm, Yoon, \& Silber, 2014; Saha vd., 2018). DWI-MR kontrastsız bir yöntem olarak meme kanserinin teşhisinde gelecek vaat etmektedir.

\section{Mamografi (MG)}

Meme kanseri tanısında mamografi en yaygın radyografik görüntüleme yöntemidir (Gierach vd., 2014; Li, Giger, Huynh, \& Antropova, 2017; Li, Giger, Lan, Janardanan, \& Sennett, 2014). Mamografi tarama yöntemi olarak kullanıldığı için hasta sayısı her zaman daha fazladır. İki boyutlu görüntü veren mamografi tümörün tanısı ve şeklinin değerlendirilmesinde etkin olamayabilir.

\section{Ultrasonografi (US)}

Radiomics alanında ultrasonografi görüntüleri kullanan yayın sayısı nispeten azdır (Grimm \& Mazurowski, 2020). Ultrasonografi görüntüleri mamografi ve MR görüntülerine kıyasla bilgilerin birbiriyle örtüşmesi zordur. Guo ve arkadaşlarının (Guo vd., 2018) ve Sun ve arkadaşlarının (Sun vd., 2020) radiomics çalışmaları ultrasonografi görüntüleri ile yapılan az sayıda çalışmalardandır.

\section{Pozitron Emisyon Tomografisi / Bilgisayarlı Tomografi (PET / BT)}

Meme kanseri tanısında tarama için mamografi kullanmak oldukça yaygındır. Ancak etkinliği meme yoğunluğu, östrojen tedavisi, yaş ve hatta ırk ile değişebilmektedir. MR ve US ile alınan görüntüler tamamlayıcı olmakla birlikte memedeki kitlenin iyi ya da kötü ayrımını yapabilmek için daha duyarı bir yöntem gerekebilir. Son yıllarda Pozitron Emisyon Tomografisi diğer yöntemlerin yanında öne çıkmaktadır ve klinisyenlere yardımcı olmaktadır.

\subsubsection{ROI (Region of Interest) ve Segmentasyon}

Meme kanseri prognozuna yardımcı olacak dokunun belirlenmesi oldukça önemlidir. Tümörün ya da şüpheli bölgenin detaylı analizi için o bölgenin veya bölgelerin doğru bir şekilde belirlenmesi radiomics aşamalarından biridir. Radiomics işlevinin en temel aşamalarından biri ilgili bölgeyi (region of interest-ROI) belirlemektir. Yani görüntüden bilgi içermeyen bölümlerin çıkarılmasıdır. Makine öğrenme algoritmalarının başarısı için değerli nitelik gereklidir. Radiomic nitelik sayısı ise ROI büyüklüğüne ve gri renk seviyelerinin sayısına bağlı olarak değişebilir.

Görüntüler yoğunluğa göre bölümlere ayrıldığında, kullanıcı ilginç nesneleri kapsayan bir dizi piksel yoğunluğu değeri tanımlar. Kullanıcı, üzerinde nesnelerin bulunduğu ve altında arka planı kapsayan gri ölçekli bir yoğunluk değeri tanımlar. İlgilenilen nesnelerin ortalama yoğunluk değerleri aralığı varsa, 0 (siyah) ile 255 (beyaz) arasında olası yoğunluk değerlerinin bir dilimini tanımlamak görüntüyü bölümlere ayırabilir ve nesneleri arka plandan ayırabilir.

İlgili bölgenin (ROI) seçilip diğer bölgelerin çıkarılması işlevi segmentasyon olarak adlandırılır. Segmentasyon bir eşik (threshold) değerine göre, bölgeye göre, modele göre, piksellere göre olabilmektedir.

\subsubsection{Nitelik Çıarımı (Feature Extraction) ve Nitelik Seçimi (Feature Selection)}

Veri dönüştürme olarak da adlandırabileceğimiz nitelik çıkarımı, görüntü verisini makine öğrenme algoritmaları yapısına uygun kantitatif veri olarak elde etmektir. Radiomics verisinde semantik ve agnostik olarak adlandırılan iki tür nitelik yapısından bahsedlir. Semantik nitelikler ilgili bölgeyi (ROI) tanımlamak için kullanılan radyoloji terminolojisinde olan boyut (size), şekil (shape), konum (location), nekroz (necrosis) gibi niteliklerdir. Agnostik nitelikler ise lezyon heterojenitesini tanımlayan histogram, Haralick ya da Laws doku nitelikleri, Minkowski fonksiyonu, Laplace dönüşümü ile elde edilen kantitatif niteliklerdir (Gillies vd., 2016). Agnostik nitelikler birinci seviye, ikinci seviye ve yüksek seviye istatistiksel işlemler içermektedir. Birinci seviye doku istatistikleri, bir görüntüdeki voksel yoğunluğunun dağılımını tanımlamaya yönelik birinci seviye histogramlarına dayanmaktadır. Burada entropi ve uniformity gibi kavramlar devreye girmektedir (V. Parekh \& Jacobs, 2016).

Nitelik seçimi büyük ölçekli ve çok boyutlu bir veri seti üzerinde çalışıldığında veri madenciliğinin en önemli aşamalarından biri olmaktadır. Veri seti içerisindeki değersiz niteliklerin çıkarılması yani en değerli niteliklerin ayrılması hem sınıflandırma doğruluğunu hem de işlem zamanını azaltacaktır (Chandrashekar \& Sahin, 2014; Deniz, Kiziloz, Dokeroglu, \& Cosar, 2017; Kira \& Rendell, 1992; Xue, Zhang, Browne, \& Yao, 2016; Zhao vd., 2015).

Nitelik seçim yöntemleri genel olarak üç gruba ayrılmaktadır: filtreleme (filter), sarmal (wrapper) ve gömülü (embedded) yöntemler. Filtreleme yöntemleri istatistiksel bilgiye dayalı olarak gerçekleştirilir. Fisher skor, t-skor, Welch-t, Ki-kare, entropi değerine bağlı Bilgi kazanımı (information gain), bilgi kazanımı bağı Kazanç oranı (gain ratio), korelasyon tabanlı yöntemler filtreleme tabanlı nitelik seçim yöntemleri olarak kullanılan başlıca yöntemler olarak sayılabilir. Sarmal nitelik seçim yöntemleri nitelikler üzerinde çeşitli arama algoritmaları kullanarak en değerli nitelikleri seçmeye çalışır. Karınca kolonisi (ant colony optimization), parçacık sürü optimizasyonu (particle swarm optimization) algoritmaları bu yönteme örnek olarak verilebilir (Zhao vd., 2015). Gömülü nitelik seçim yöntemleri nitelik seçimi ve sınıflandırma algoritmalarını aynı anda içeren daha yüksek hesaplama maliyetine sahip yapılardır. Örneğin Lasso ve random forest gibi makine öğrenme algoritmalarının yapılarına uygun kendi nitelik seçim algoritmaları vardır (Xue vd., 2016; Zhao vd., 2015).

\section{Araştırma Sonuçları ve Tartışma}

Meme kanseri alanında ilk radiomics çalışması Yamamoto ve arkadaşları tarafından 10 meme kanseri hastasının DCE-MRI görüntüleri üzerinden yapılmıştır (Yamamoto vd., 2012). Radyografik görüntülerden elde edilen radiomics verilerinin geleneksel 
istatistiksel yöntemler dışında yapay zeka yöntemleri (makine öğrenme, derin öğrenme algoritmaları) kullanılarak analizi hakkında araştırmaların sayısı hızla artmaktadır.

Li ve arkadaşları 456 MG görüntüsü üzerinde Bayes Yapay Sinir Ağı (Bayesian Artificial Nneural Network-ANN) kullanarak bir model geliştirmiş ve AUC (Area Under the Curve) değerini 0.81 olarak elde etmişlerdir (Li vd., 2014). Gierach ve arkadaşları Bayes yapay sinir ağları ile 166 eğitim ve 60 test verisinden oluşan MG görüntüleri üzerinde Bayes yapay sinir ağları (Bayesian ANN) ile AUC değerini 0.72 bulmuşlardır (Gierach vd., 2014). Li ve arkadaşları $456 \mathrm{MG}$ görüntüden oluşan veriye bu kez derin öğrenme yöntemi olan Konvolüsyonel Sinir Ağları (Convolution Neural Network-CNN) modelini uygulanmış ve AUC değerini 0.83 olarak elde etmişlerdir (Li vd., 2017).

Rodriguez ve arkadaşları (Rodriguez-Ruiz vd., 2019) 653 ü malign toplam 2652 hastanın DMT MG görüntülerinden elde edilen radyomic niteliklerle oluşturulan CNN modelin performansını 101 uzman radyologun birbirinden bağımsız değerlendirme sonuçları ile karşılaştırmıştır. 101 radyologun analizinin ortalaması AUC değeri 0.81 iken CNN modelin AUC değeri 0.84 olarak elde edilmiş̧tir. Saha ve arkadaşları (Saha vd., 2018) bazı biyobelirteçlerle (human epidermal growth factor receptor 2 -HER2, estrogen receptor -ER, progesterone receptor-PR gibi) farklı tümör alt tiplerini ayırt etmeye çalş̧an makine öğrenme tabanlı çok değişkenli bir model geliştirdiler. Random Forest makine öğrenme algoritmasını kullanarak sınıflandırdıkları model en iyi Luminal A alt tipini AUC $=0.697$ değeri ile ayırt edebilmiştir. En güçlü ilişki Östrojen (ER) ve Progesteron (PR) biyoloçleri ile sırasıyla AUC değerleri 0.649 ve 0.622 olarak bulunmuştur.

Guo ve arkadaşları (Guo vd., 2018) invaziv duktal karsinomu olan 215 hastanın ultrasonografi görüntülerinden elde edilen kantitatif nitelikler ve biyobelirteçler arasında ilişkiyi değerlendirmek amacıyla otomatik bir radiomics model önermiş̧lerdir. Makine öğrenme algoritmalarından Destek Vektör Makineleri (Support Vector Machines-SVM) sınıflayıcısı kullanılarak model geliştirilmiştir. 463 radiomic nitelikten LASSO nitelik seçim yöntemi ile 36 en değerli nitelik seçilmiştir. Sonuç olarak seçilen 36 nitelik ile geliştirilen radiomics model sınıflandırılmış ve tümör alt tipleri ve biyobelirteçler arasında güçlü bir korelasyon göstermiştir (AUC=0.76).

Ribli ve arkadaşları (Ribli, Horváth, Unger, Pollner, \& Csabai, 2018), MG görüntülerinde bir lezyonun iyi ya da kötü huylu olduğunu sınıflayan bir derin öğrenme modeli geliştirmişlerdir. Geliştirdikleri Faster R-CNN modeli, Inbreast (Moreira vd., 2012) veri seti üzerinde AUC $=0.95$ değeri ile yüksek bir başarı göstermiştir. Aynı model DDSM (M. Heath, K. Bowyer, D. Kopans, 2001) veri seti üzerinde $\mathrm{AUC}=0.85$ değeri ile başarılı bir performans göstermiştir. Herent ve arkadaşları (Herent vd., 2019) MR görüntülerinden elde edilen radiomics niteliklerle memedeki bir lezyonun iyi ya da kötü huylu olmasını ayırt etmeye çalışan bir derin öğrenme modeli geliştirdiler. Geliştirdikleri ResNet (Residual Neural Network) (He, Zhang, Ren, \& Sun, 2016) derin öğrenme modelinin performansını 335 hastadan alınan görüntülerden radiomics nitelikler çıartmak için kullandılar ve 0.82 AUC değeri ile başarılı bir sonuç elde ettiler.

Sun ve arkadaşları (Sun vd., 2020) meme kanseri tedavisinde önemli olan aksiller lenf nodu (ALN) metastaz durumunu derin öğrenme ile değerlendiren bir model geliştirdiler. Mammografi görüntülerini kullanarak ALN metastazını tahmin etmek amacıyla klasik radiomics analiz ile geliştirilen model ile CNN modelini karşılaştırdılar. 479 meme kanseri hastasına ait 2395 US görüntü kullanılarak intra-tümoral, peri-tümoral ve intra-peri-tümoral olmak üzere üç bölge için üç CNN model DenseNet kullanılarak geliştirildi. Aynı zamanda Random Forest (RF) makine öğrenme algoritması kullanılarak üç radiomics model geliştirildi. Bu altı model 343 hastanın 680 görüntüsünden oluşan eğitim verisi ile oluşturuldu. Test verisi olarak geriye kalan 136 hastanın 680 görüntüsü ile değerlendirilen modellerde genel olarak CNN modeller daha yüksek başarı göstermiştir. Intra-peri-tümoral kombine bölgede hem CNN model ( $\mathrm{AUC}=0.957$ ) hem de $\mathrm{RF}$ model ( $\mathrm{AUC}=0.940$ ) diğer bölgelere göre daha yüksek sonuç vermiştir.

Tablo 1. Meme kanseri üzerindeki Radiomics ile birlikte yapay zeka yöntemlerini kullanan yayınlar

\begin{tabular}{lcccc}
\hline Yayın & Yöntem & $\begin{array}{c}\text { Görüntüleme } \\
\text { Yöntemi }\end{array}$ & $\begin{array}{c}\text { Hasta Sayısı } \\
\text { (Eğitim+Test) }\end{array}$ & Başarı \\
\hline Li ve ark. (Li vd., 2014) & $\begin{array}{c}\text { Makine Öğrenme } \\
\text { Bayesian ANN } \\
\text { Makine Öğrenme } \\
\text { Bayesian ANN }\end{array}$ & MG & 456 & AUC $=0.81$ \\
Gierach ve ark. (Gierach vd., 2014) & $\begin{array}{c}\text { Merin Öğrenme } \\
\text { CNN }\end{array}$ & MG & $177+60$ & AUC $=0.72$ \\
Li ve ark. (Li vd., 2017) & $\begin{array}{c}\text { Makine Öğrenme } \\
\text { SVM }\end{array}$ & US & 215 & AUC $=0.83$ \\
Guo ve ark. (Guo vd., 2018) & $\begin{array}{c}\text { Makine Öğrenme } \\
\text { Random Forest }\end{array}$ & MR & $461+461$ & AUC $=0.76$ \\
Saha ve ark. (Saha vd., 2018) & $\begin{array}{c}\text { Derin Öğrenme } \\
\text { Faster R-CNN }\end{array}$ & MG & 115 (Inbreast) & AUC $=0.697$ \\
Ribli ve ark. (Ribli vd., 2018) & $\begin{array}{c}\text { Derin Öğrenme } \\
\text { CNN }\end{array}$ & MG & 2620 (DDSM) & AUC $=0.95$ \\
Rodriguez ve ark. (Rodriguez-Ruiz & $\begin{array}{c}\text { Derin Öğrenme } \\
\text { vd., 2019) }\end{array}$ & MR & 335 & AUC $=0.84$ \\
Herent ve ark. (Herent vd., 2019) & Residual Neural Network \\
Derin Öğrenme & CNN & US & $343+136$ & AUC $=0.82$ \\
Sun ve ark. (Sun vd., 2020) & & & AUC $=0.95$ \\
\hline
\end{tabular}




\section{Sonuç}

Meme kanseri teşhis ve prognozunda radiomics uygulamalarından yararlanılması oldukça yeni ve gelişmekte olan bir araştırma alanıdır. Radiomics, dijital radyografik görüntülerden büyük miktarda kantitatif nitelik çıkararak bu büyük veri ile veri setleri oluşturmayı hedefler. Amaç bir karar destek sistemi geliştirmektir. Çok sayıda hastadan gelen görüntülerden elde edilen sayısal bilgiler karar destek sisteminin gücünü arttıracaktır. Böylelikle radiomics ve genomics birarada biyobelirteçlerden yararlanarak kanserin teşhisi ve prognozun değerlendirilmesi, tedaviye yanıtın ön görülmesi ve hastalık durumunun izlenmesi hedeflenmektedir (Gillies vd., 2016; Lambin vd., 2012). Ancak çalışmalarda kullanılan veri standartları örtüşmediğinden çalışma performanslarını test etmek oldukça zor olmaktadır. Verinin kalitesi, güvenilirliği ve miktarı yapay zeka yöntemlerini kullanırken fark yaratmaktadır. Gen bilgilerinin öneminin anlaşıldığı bu dönemde genomics profilleri, histolojiyi, biyobelirteçleri ve hastanın hikayesini kapsayan radiomics modeller çok daha iyi sonuç verecektir. Son yıllarda modellerin makine öğrenmeden derin öğrenmeye doğru evrildiğini görmekteyiz. Bilgisayar işlemci hızlarının artması hem GPU ların devreye girmesiyle yapay sinir ağları üzerinde yapılan çalışmalar artmış ve farklı modeller geliştirilmiştir. Yeni teknolojilerin radyoloji alanında klinisyenlere destek verebilmesi için iş birliği ile ortak çalışmalar yapılması gerekmektedir.

\section{Kaynakça}

Chandrashekar, G., \& Sahin, F. (2014). A survey on feature selection methods. Computers \& Electrical Engineering, 40(1), 16-28. https://doi.org/10.1016/j.compeleceng.2013.11.024

Deniz, A., Kiziloz, H. E., Dokeroglu, T., \& Cosar, A. (2017). Robust multiobjective evolutionary feature subset selection algorithm for binary classification using machine learning techniques. Neurocomputing, 241, 128-146. https://doi.org/10.1016/J.NEUCOM.2017.02.033

Ferlay, J., Colombet, M., Soerjomataram, I., Mathers, C., Parkin, D. M., Piñeros, M., ... Bray, F. (2019, Nisan 15). Estimating the global cancer incidence and mortality in 2018: GLOBOCAN sources and methods. International Journal of Cancer. Wiley-Liss Inc. https://doi.org/10.1002/ijc.31937

Gierach, G. L., Li, H., Loud, J. T., Greene, M. H., Chow, C. K., Lan, L., ... Giger, M. L. (2014). Relationships between computerextracted mammographic texture pattern features and BRCA1/2 mutation status: A cross-sectional study. Breast Cancer Research, 16(4), 424. https://doi.org/10.1186/s13058-014-0424-8

Gillies, R. J., Kinahan, P. E., \& Hricak, H. (2016). Radiomics: Images Are More than Pictures, They Are Data. Radiology, 278(2), 563577. https://doi.org/10.1148/radiol.2015151169

Grimm, L. J., \& Mazurowski, M. A. (2020, Ocak 1). Breast Cancer Radiogenomics: Current Status and Future Directions. Academic Radiology. Elsevier USA. https://doi.org/10.1016/j.acra.2019.09.012

Guo, Y., Hu, Y., Qiao, M., Wang, Y., Yu, J., Li, J., \& Chang, C. (2018). Radiomics Analysis on Ultrasound for Prediction of Biologic Behavior in Breast Invasive Ductal Carcinoma. Clinical Breast Cancer, 18(3), e335-e344. https://doi.org/10.1016/j.clbc.2017.08.002

He, K., Zhang, X., Ren, S., \& Sun, J. (2016). Deep residual learning for image recognition. Içinde Proceedings of the IEEE Computer Society Conference on Computer Vision and Pattern Recognition (C. 2016-Decem, ss. 770-778). https://doi.org/10.1109/CVPR.2016.90

Herent, P., Schmauch, B., Jehanno, P., Dehaene, O., Saillard, C., Balleyguier, C., ... Jégou, S. (2019). Detection and characterization of MRI breast lesions using deep learning. Diagnostic and Interventional Imaging, 100(4), $219-225$. https://doi.org/10.1016/j.diii.2019.02.008

Kira, K., \& Rendell, L. A. (1992). A Practical Approach to Feature Selection. Içinde Machine Learning Proceedings 1992 (ss. 249 256). Elsevier. https://doi.org/10.1016/B978-1-55860-247-2.50037-1

Lambin, P., Rios-Velazquez, E., Leijenaar, R., Carvalho, S., Van Stiphout, R. G. P. M., Granton, P., ... Aerts, H. J. W. L. (2012). Radiomics: Extracting more information from medical images using advanced feature analysis. European Journal of Cancer, 48(4), 441-446. https://doi.org/10.1016/j.ejca.2011.11.036

Li, H., Giger, M. L., Huynh, B. Q., \& Antropova, N. O. (2017). Deep learning in breast cancer risk assessment: evaluation of convolutional neural networks on a clinical dataset of full-field digital mammograms. Journal of Medical Imaging, 4(04), 1. https://doi.org/10.1117/1.jmi.4.4.041304

Li, H., Giger, M. L., Lan, L., Janardanan, J., \& Sennett, C. A. (2014). Comparative analysis of image-based phenotypes of mammographic density and parenchymal patterns in distinguishing between BRCA1/2 cases, unilateral cancer cases, and controls . Journal of Medical Imaging, 1(3), 031009. https://doi.org/10.1117/1.jmi.1.3.031009

M. Heath, K. Bowyer, D. Kopans, R. M. and P. K. J. (2001). The Digital Database for Screening Mammography. Içinde the Fifth International Workshop on Digital Mammography, M.J. Yaffe, ed., Medical Physics Publishing, 2001. (ss. 212-218). https://doi.org/ISBN 1-930524-00-5

Mazurowski, M. A., Zhang, J., Grimm, L. J., Yoon, S. C., \& Silber, J. I. (2014). Radiogenomic analysis of breast cancer: Luminal B molecular subtype is associated with enhancement dynamics at MR imaging. Radiology, 273(2), 365-372. https://doi.org/10.1148/radiol.14132641

Moreira, I. C., Amaral, I., Domingues, I., Cardoso, A., Cardoso, M. J., \& Cardoso, J. S. (2012). INbreast: Toward a Full-field Digital Mammographic Database. Academic Radiology, 19(2), 236-248. https://doi.org/10.1016/j.acra.2011.09.014

Parekh, V., \& Jacobs, M. A. (2016). Radiomics: a new application from established techniques. Expert Review of Precision Medicine and Drug Development. https://doi.org/10.1080/23808993.2016.1164013

Parekh, V. S., \& Jacobs, M. A. (2019, Mart 4). Deep learning and radiomics in precision medicine. Expert Review of Precision Medicine 
and Drug Development. Taylor and Francis Ltd. https://doi.org/10.1080/23808993.2019.1585805

Ribli, D., Horváth, A., Unger, Z., Pollner, P., \& Csabai, I. (2018). Detecting and classifying lesions in mammograms with Deep Learning. Scientific Reports, 8(1), 1-7. https://doi.org/10.1038/s41598-018-22437-z

Rodriguez-Ruiz, A., Lång, K., Gubern-Merida, A., Broeders, M., Gennaro, G., Clauser, P., ... Sechopoulos, I. (2019). Stand-Alone Artificial Intelligence for Breast Cancer Detection in Mammography: Comparison With 101 Radiologists. Journal of the National Cancer Institute, 111(9), 916-922. https://doi.org/10.1093/jnci/djy222

Saha, A., Harowicz, M. R., Grimm, L. J., Kim, C. E., Ghate, S. V., Walsh, R., \& Mazurowski, M. A. (2018). A machine learning approach to radiogenomics of breast cancer: A study of 922 subjects and 529 dce-mri features. British Journal of Cancer, 119(4), 508-516. https://doi.org/10.1038/s41416-018-0185-8

Sun, Q., Lin, X., Zhao, Y., Li, L., Yan, K., Liang, D., ... Li, Z. C. (2020). Deep Learning vs. Radiomics for Predicting Axillary Lymph Node Metastasis of Breast Cancer Using Ultrasound Images: Don't Forget the Peritumoral Region. Frontiers in Oncology, 10. https://doi.org/10.3389/fonc. 2020.00053

World Health Organization. (2020). WHO. Tarihinde adresinden erişildi https://www.who.int/cancer/countryprofiles/Global_Cancer_Profile_2020.pdf

Xue, B., Zhang, M., Browne, W. N., \& Yao, X. (2016). A Survey on Evolutionary Computation Approaches to Feature Selection. IEEE Transactions on Evolutionary Computation, 20(4), 606-626. https://doi.org/10.1109/TEVC.2015.2504420

Yamamoto, S., Maki, D. D., Korn, R. L., \& Kuo, M. D. (2012). Radiogenomic analysis of breast cancer using MRI: A preliminary study to define the landscape. American Journal of Roentgenology, 199(3), 654-663. https://doi.org/10.2214/AJR.11.7824

Zhao, X., Li, D., Yang, B., Chen, H., Yang, X., Yu, C., \& Liu, S. (2015). A two-stage feature selection method with its application. Computers \& Electrical Engineering, 47, 114-125. https://doi.org/10.1016/J.COMPELECENG.2015.08.011 